\title{
Variations of atmospheric aerosol parameters in periods of seismic activity in Tien-Shan
}

\author{
Leonid Sverdlik ${ }^{1, *}$ \\ ${ }^{1}$ Research Station of the Russian Academy of Sciences in Bishkek, Kyrgyzstan
}

\begin{abstract}
Combination of numerical modeling (MERRA) and groundbased (AERONET) monitoring of atmospheric aerosol parameters were used to discover a possible connection to seismic activities within the territory of Tien-Shan. The obtained results demonstrated consistent behavior between increase of aerosol optical thickness (AOT) and powerful earthquakes, epicenters of which were located within $200 \mathrm{~km}$ from the "Issyk-Kul" station (AERONET). Thereat, the dominant role was played by fine-dispersed particles, which virtually determined the nature of AOT evolution. We also observed well-defined changes of the ratio between mass fraction $\mathrm{PM}_{1.0}$ (particles less than $1.0 \mu \mathrm{m}$ aerodynamic diameter) and optical thickness of aerosol scattering several days before an earthquake of $\mathrm{M}>5.0$ magnitude.
\end{abstract}

\section{Introduction}

By now numerous anomalies, observed before seismic events both on the Earth's surface and in the atmosphere and ionosphere, have been detected while a reliable earthquake forecast is still one of the most important unsolved geophysics problems, which assumes a necessity to investigate physical characteristics of all the complex of phenomena in geospheres. An important aspect from the point of view of understanding of lithospheric-atmospheric interrelation during seismic activities is investigation of spatial and temporal variations of atmospheric parameters and atmosphere aerosol characteristics in particular [1]. Aerosols play a significant part in the Earth's radiation balance [2], regional and global climate changes and the also influence on air quality and public health. In a series of researches particulate matter optical properties were used as indicators of pre-seismic anomalies [3]. Thereat, changes of atmospheric aerosol optical thickness (AOT) are analyzed more often. Thus, assessments of AOT changes, occurred before strong earthquakes in Chile (2010) and in Nepal (2015), showed an express increase (approximately by $40 \%$ ) in vicinity of the epicenter several days before the main event [4]. Anomalies in AOT temporal and spatial variations were observed before, during and after each of eight strong earthquakes of $M>$ 8.0 [5]. Investigations of relationship between large seismic events and anomalous variations of aerosol optical parameters are based on data of both land and spaceborne remote sensing

\footnotetext{
* Corresponding author: 1 .sverdlik@mail.ru
} 
[1]. The most accurate information on atmospheric aerosol parameters are obtained due to measurements with CIMEL sun photometers, which are used in the global ground-based aerosol observation network, AERONET [6]. The data may be effectually used in seismically active regions in vicinity of AERONET stations. In recent years, satellite measurements, allowing analysis of atmospheric properties changes on a global basis, have become widely used to monitor all types of hazardous natural phenomena. Combination of the two information sources is most effective and, accordingly, it was used in this study. For the quantitative assessment of the aerosol content in the atmosphere, results of ground-based measurements of spectral AOT before and after earthquakes were used. Satellite time series of various combinations of parameters and particularly those providing important information in relation to the ratio between aerosol scattering properties and the mass fraction of particulate matter with aerodynamic diameter of less than $1.0 \mu \mathrm{m}\left(\mathrm{PM}_{1.0}\right)$.

\section{Initial data}

Ground-based and satellite data for periods of preparation of 12 strong earthquakes (EQ) characterized by magnitudes of $\mathrm{M}>5.0$ occurred within the territory limited by the following coordinates: $39-44^{\circ} \mathrm{N}, 70-80^{\circ} \mathrm{E}$ in $2003-2018$ have been analyzed (Table 1). Information on seismic events were obtained from the earthquake catalog composed on the basis of data of the KNET regional seismological network [7] and the online version of the U.S. Geological Survey (USGS) global catalog [8].

Table 1. Characteristics of the study sample of seismic events $(M>5.0)$.

\begin{tabular}{|c|c|c|c|c|c|c|}
\hline EQ & Date & Time & Latitude & Longitude & Depth, km & M \\
\hline 01 & 22.05 .2003 & $18: 11: 56$ & $42.95^{\circ} \mathrm{N}$ & $72.76^{\circ} \mathrm{E}$ & 33.0 & 5.5 \\
\hline 02 & 16.01 .2004 & $09: 06: 21$ & $42.53^{\circ} \mathrm{N}$ & $75.35^{\circ} \mathrm{E}$ & 27.5 & 5.0 \\
\hline 03 & 08.01 .2007 & $17: 21: 50$ & $39.80^{\circ} \mathrm{N}$ & $70.31^{\circ} \mathrm{E}$ & 16.0 & 6.0 \\
\hline 04 & 17.03 .2011 & $15: 34: 35$ & $40.48^{\circ} \mathrm{N}$ & $79.10^{\circ} \mathrm{E}$ & 32.8 & 5.0 \\
\hline 05 & 09.04 .2011 & $12: 30: 26$ & $42.07^{\circ} \mathrm{N}$ & $74.82^{\circ} \mathrm{E}$ & 14.4 & 5.0 \\
\hline 06 & 28.01 .2013 & $16: 38: 54$ & $42.61^{\circ} \mathrm{N}$ & $79.71^{\circ} \mathrm{E}$ & 15.0 & 6.1 \\
\hline 07 & 23.11 .2013 & $09: 42: 08$ & $42.53^{\circ} \mathrm{N}$ & $75.71^{\circ} \mathrm{E}$ & 9.8 & 5.0 \\
\hline 08 & 14.11 .2014 & $01: 24: 17$ & $42.09^{\circ} \mathrm{N}$ & $77.26^{\circ} \mathrm{E}$ & 10.1 & 5.2 \\
\hline 09 & 17.11 .2015 & $17: 29: 36$ & $40.38^{\circ} \mathrm{N}$ & $73.20^{\circ} \mathrm{E}$ & 18.0 & 5.6 \\
\hline 10 & 19.07 .2016 & $12: 32: 56$ & $41.55^{\circ} \mathrm{N}$ & $79.01^{\circ} \mathrm{E}$ & 10.0 & 5.1 \\
\hline 11 & 26.03 .2018 & $12: 53: 50$ & $43.72^{\circ} \mathrm{N}$ & $77.33^{\circ} \mathrm{E}$ & 29.0 & 5.0 \\
\hline 12 & 14.09 .2018 & $22: 15: 03$ & $41.85^{\circ} \mathrm{N}$ & $77.13^{\circ} \mathrm{E}$ & 18.0 & 5.0 \\
\hline
\end{tabular}

Initial data on atmospheric aerosol parameters were obtained at the "Issyk-Kul" station, which is a part of the AERONET global network [9], the data are represented by AOT daily means of reliable quality (Level 2.0), as well as data of Level 1.5 (cloud screening), that have a higher error of atmosphere optical parameters reconstruction, but provide a better measurement statistics [10]. Satellite remote sensing data, processed in the MERRA model (Time Series; Area-Averaged of Dust Scattering AOT $550 \mathrm{~nm}$ - PM $1.0 \mu \mathrm{m}$; M2T1NXADG v5.12.4) were used as a means of global monitoring of variability of aerosol characteristics [11], in this particular case, optical thickness of aerosol scattering at the wavelength $550 \mathrm{~nm}$ for mass concentration of fine particles $\mathrm{PM}_{1.0}$, were used. Both time series of the parameter with discretization of $\Delta t=1$ hour above areas of $\pm 1^{\circ}$ in size from earthquake epicenters, and its spatial distribution in the area of the seismic focus of each event [12] were recovered. 


\section{Consideration of the results}

\subsection{Aerosol parameters variations according to land measurement data}

Investigation of possible relationship between the atmosphere aerosol load and seismic activities in Tien-Shan was performed using land observation data. For this purpose the strongest seismic events, epicenters of which were located within $\sim 200 \mathrm{~km}$ from the AERONET station were selected. One of that kind of earthquakes of magnitude 6.1 was registered on January 28, 2013 on the border between Kyrgyzstan and Kazakhstan (Fig. 1a). Fig. 1b illustrates AOT (Level 1.5) variations in the spectral range from 340 to $1020 \mathrm{~nm}$ in periods from January 4 to February 4, 2013. As it appears from the presented diagrams, the aerosol optical thickness in the short-wave region of the spectrum $(340-500 \mathrm{~nm})$ achieved maximum values $(0.400-0.550) 1-6$ days before the seismic event.
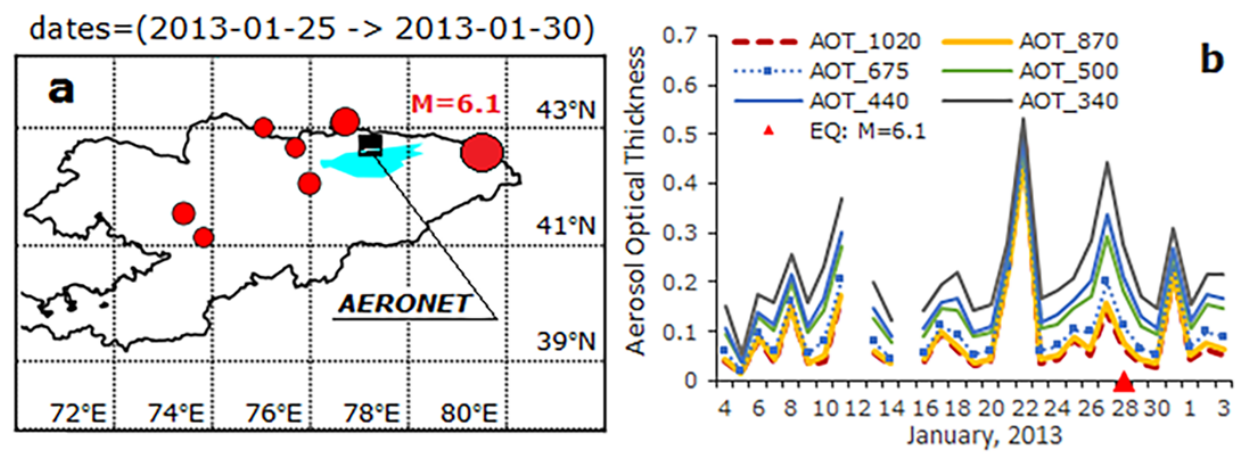

Fig. 1. Locations of the AERONET station (42.623 N, 76.983 E) and earthquake epicenters (a) and change of daily means of spectral AOT (Level 1.5) in January 2013 (b). The marker shows the earthquake of magnitude $\mathrm{M}=6.1$ (January 28, 2013).

AOT observation data, adjusted according to results of recalibration (Level 2.0), were detailed using fine $\left(\mathrm{AOT}_{\mathrm{F}}\right)$ and coarse $\left(\mathrm{AOT}_{\mathrm{C}}\right)$ modal constituents. The sum of the fine- and coarse-mode AOTs constitutes the total AOT. As is shown in Fig. 2, the highest value of the optical thickness (0.325) at the wavelength of $440 \mathrm{~nm}$ was observed a day before an earthquake of magnitude 6.1 .

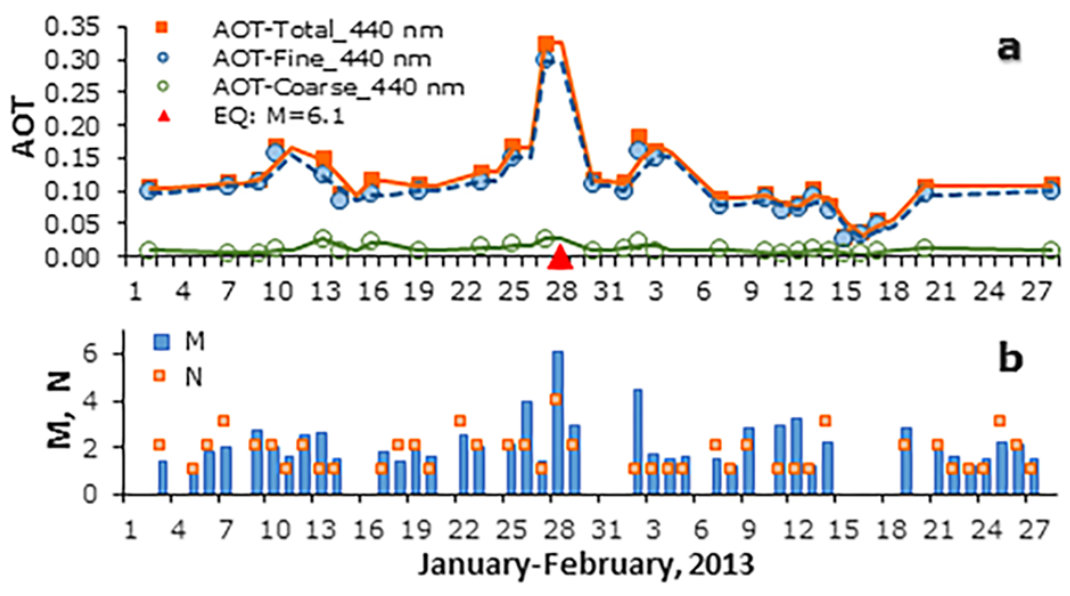

Fig. 2. Variations of $\mathrm{AOT}, \mathrm{AOT}_{\mathrm{F}}$ and $\mathrm{AOT}_{\mathrm{C}}$ (Level 2.0) daily means with time at the wavelength of $440 \mathrm{~nm}$ (a) and seismic activities (b) in January-February 2013. 
Assessments of the contribution of two aerosol fractions demonstrate that the dominant role was played by fine-dispersed particles, which virtually determined the nature of the AOT evolution. Apparent consistency of behavior between AOT $_{F}$ variations (Fig. 2a) and the seismicity, which is represented by a sequence of magnitudes (M) and the number of events (N) (Fig. 2b), allows to make an assumption as to possible sources of aerosol particles. One a the reasons of finely dispersed aerosol domination in the atmosphere may be nucleation processes emerging in the course of ionization of near-ground atmospheric layer and planetary boundary layer [7].

Another example of photometric measurements in periods of preparation and occurrence of earthquakes of magnitude $M>5.0$ (September 3 and 14, 2018) may be results of calculation of AOT (Level 1.5) daily means at the wavelength of $340 \mathrm{~nm}$ and corresponding variations of fine mode fraction (FMF) contribution into the aerosol optical thickness in August-September 2018 (Fig. 3a). As we can see, in periods preceding strong earthquakes changes in particle size distribution of atmospheric aerosol were observed. Increased AOT values were generally determined by fine-dispersed particles (Fig. 3b).
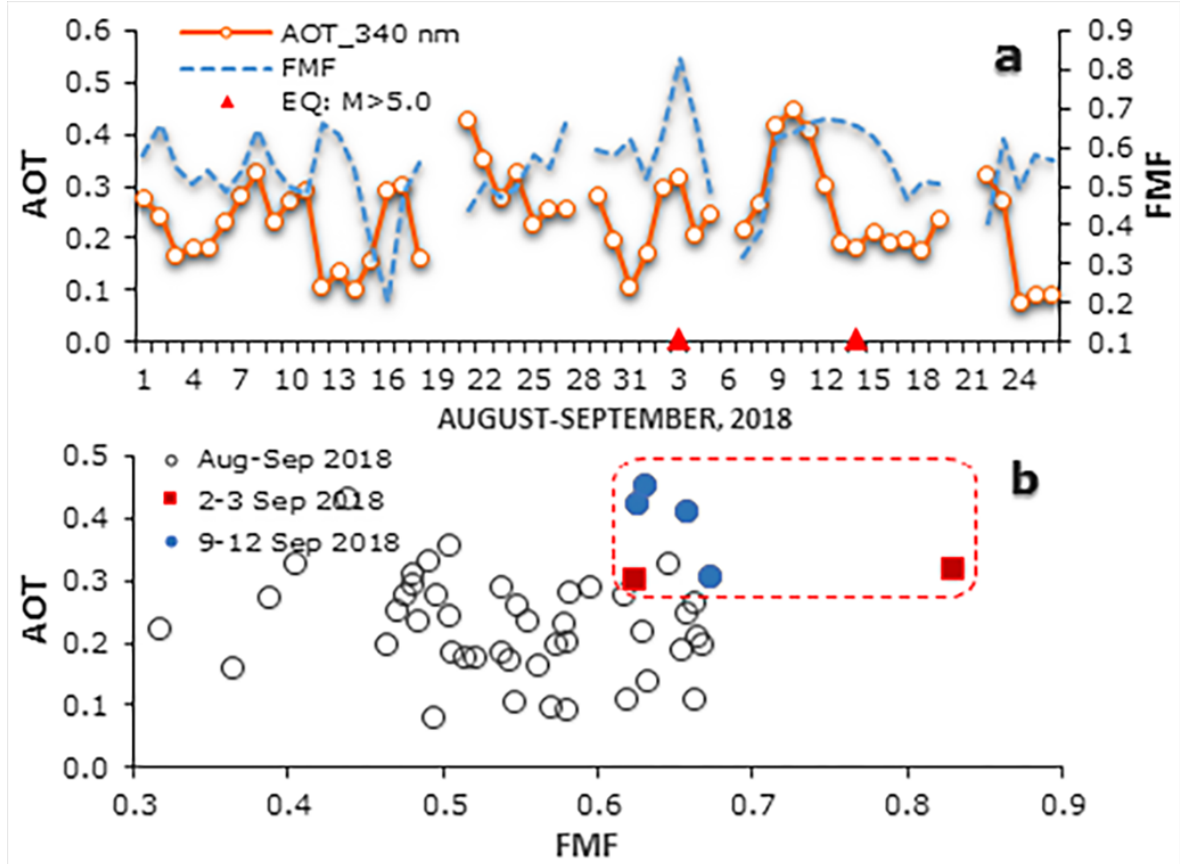

Fig. 3. Time series of AOT (Level 1.5) daily means at the wavelength of $340 \mathrm{~nm}$ and fine mode fraction (FMF) relative contribution into the aerosol optical thickness in August-September 2018 (a). The markers indicate earthquakes of $M>5.0$ (September 3 and 14, 2018). Interrelation between AOT and FMF in periods of seismic activities (b).

\subsection{Results of satellite measurements of aerosol parameters}

Processes, taking place in geospheres in the course of preparation of strong earthquakes, may result in formation of aerosols, size distribution of which differs from that observed in periods without seismic events. Such peculiarities of particle size spectra pre-seismic variations were detected using the $\mu=\mathrm{AOT} / \mathrm{PM}_{1.0}$ parameter, characterizing relation between mass concentration and optical thickness of aerosol scattering [8]. Preliminary results of satellite data processing in the form of normalized ratios $1 / \mu$, normalized to one earthquake moment, are presented in Fig. 4. Apparent well-defined changes $1 / \mu$, preceding strong earthquakes of 
$M \geq 5.0$ by $1-5$ days may be probably attributed to presence of predominantly fine-dispersed particles, which have a great impact on AOT, but insignificantly change $\mathrm{PM}_{1.0}$.

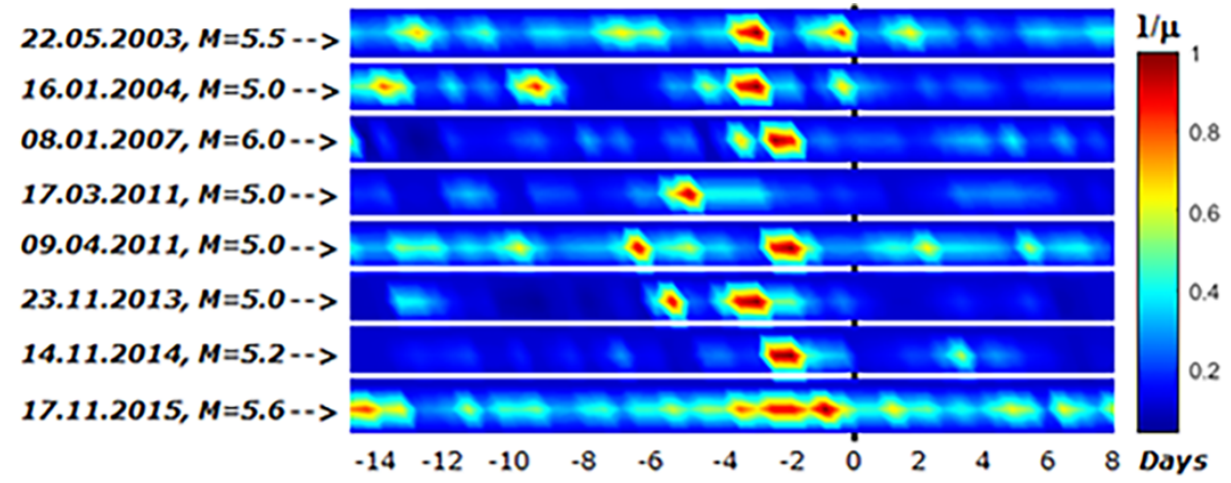

Fig. 4. Distribution of normalized ratios $1 / \mu$ in periods starting on 15 days before and ending 7 days after each event $M>5.0$ in Tien-Shan.

Spatial distribution of the Dust Scattering $\mathrm{AOT}_{550 \mathrm{~nm}}-\mathrm{PM}_{1.0} \mu \mathrm{m}$ parameter a day before strong earthquakes, occurred on November 17, $2015(\mathrm{M}=5.6)$, July 19, $2016(\mathrm{M}=5.1)$, March 26, $2018(\mathrm{M}=5.0)$ and September 14, $2018(\mathrm{M}=5.0)$, is presented in Fig. 5. Local maximums of $1 / \mu$ were observed near epicenters one day before earthquakes.

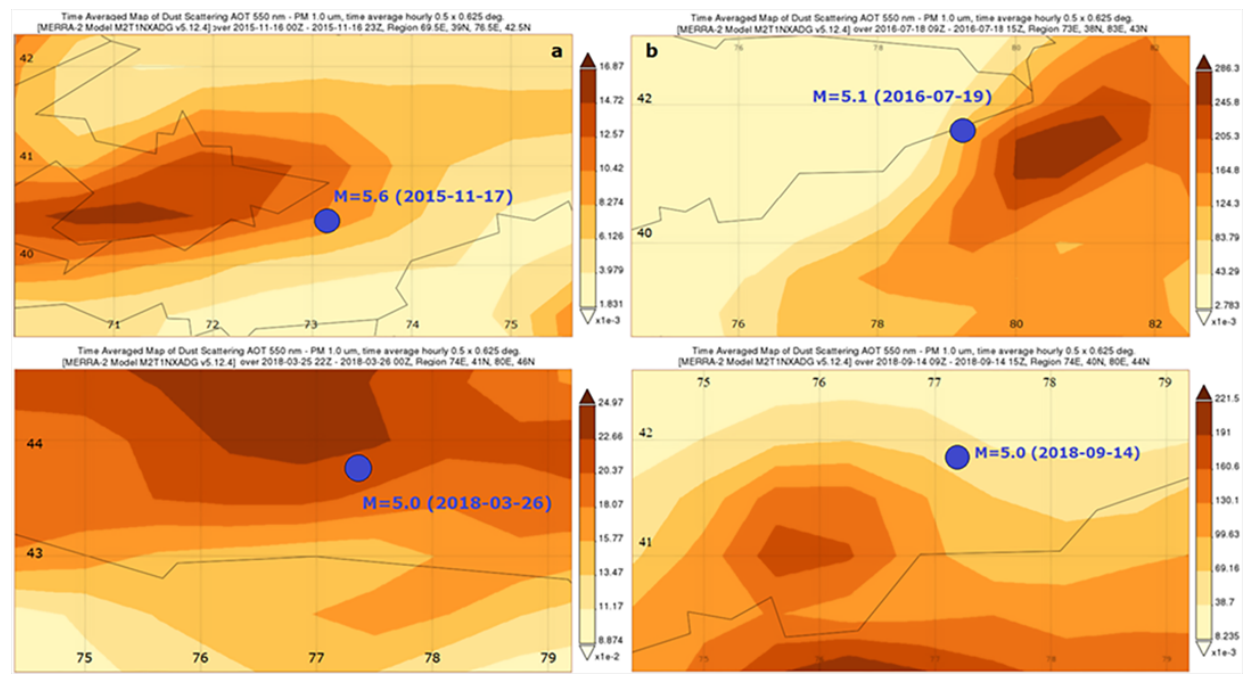

Fig. 5. Spatial distribution of Scattering $\mathrm{AOT}_{550 \mathrm{~nm}}-\mathrm{PM}_{1.0 \mu \mathrm{m}}$ one day before strong earthquakes of $\mathrm{M}$ > 5.0: November 17, 2015 (a); July 19, 2016 (b); March 26, 2018 (c) and September 14, 2018 (d).

\section{Conclusion}

Results of land (AERONET) and satellite (MERRA) measurements of atmospheric aerosol parameters against several events of seismic activity in the territory of Tien-Shan have been analyzed. Periods preceding strong earthquakes, epicenters of which were located within $\sim 200 \mathrm{~km}$ from the AERONET station have been examined. Analysis of ground-based remote sensing demonstrated apparent anomalous changes of the aerosol optical thickness (AOT > 0.3 ) several days before the earthquake. Thereat, dominating contribution to increased values of the aerosol optical thickness was made by fine-dispersed particles (FMF > 0.6), which 
virtually determined the nature of AOT evolution. The changes of the aerosol characteristics may be associated with seismic events.

An important aspect from the point of view of understanding of lithospheric-atmospheric interrelation during seismic activities is investigation of not only temporal variations, but spatial distribution of aerosol characteristics as well. Atmospheric effects accompanying processes of preparation of strong earthquakes in the form of change of the ratio of aerosol scattering optical thickness at the wavelength of $550 \mathrm{~nm}$ to mass fraction of particulate matter with aerodynamic diameter of less than $1.0 \mu \mathrm{m}\left(\mathrm{PM}_{1.0}\right)$. Spatial distribution of the parameter was characterized by presence of local maximums observed one day before strong earthquakes of $M>5.0$ near epicenters of the events under examination.

The above examples confirm presence of characteristic features in the temporal dynamics of atmospheric aerosol parameters in pre-seismic period. However, the results obtained are only preliminary and require a more detailed investigation.

\section{Acknowledgements}

The author is grateful to Giovanni team of NASA GES DISC for free access to satellite measurement data and modeling results. I also thank the NASA Goddard AERONET team led by Dr. B. Hoblen and station manager M. Orozaliev for producing surface observations at Issyk-Kul station.

The study is partially performed within the framework of the state task of the Federal State Budgetary Institution of Science, Research Station of Russian Academy of Sciences in Bishkek (theme No. AAAA-A19-119020190064-9).

\section{References}

1. Q. Liu, X. Shen, J. Zhang, J. Cui, S. Zhao, Geophysical Research Abstracts. 21, 3938 (2019).

2. L.G. Sverdlik, Bulletin of the Kyrgyz-Russian Slavic University. 12, 156 (2018).

3. Z-H. Jiao, J. Zhao, X. Shan, Nat. Hazards Earth Syst. Sci. 4, 1013 (2018).

4. S.A. Pulinets, D.P. Ouzounov, D.V. Davidenko, Moscow. Trovant Publ. 144 (2014).

5. M. Akhoondzadeh, F.J. Chehrebargh, Advances in Space Research. 58, 890 (2016).

6. D.M. Giles, A. Sinyuk, M.G. Sorokin, J.S. Schafer, A Smirnov., I. Slutsker, T.F. Eck, B.N. Holben, J.R. Lewis, J.R. Campbell, E.J. Welton, S.V. Korkin, A.I. Lyapustin, Atmos. Meas. Tech.. 12, 169 (2019).

7. Earthquakes catalog of Institute of Seismology of NAS KR and Research Station of RAS in Bishkek.

8. URL: https://earthquake.usgs.gov/earthquakes/.

9. URL: https://aeronet.gsfc.nasa.gov/.

10. L.G. Sverdlik, Science, new technologies and innovations. 3, 3 (2013).

11. C.A. Randles, A.M. Da Silva, V. Buchard, P.R. Colarco, A. Darmenov, R. Govindaraju, A. Smirnov, B. Holben, R. Ferrare, J. Hair, Y. Shinozuka, C.J. Flynn, J. Clim. 30. 17, 6823 (2017).

12. URL to Reproduce Results: http://giovanni.gsfc.nasa.gov/. 